DOI: 10.12731/2658-6649-2019-11-5-87-93

УДК 316.443:614.2

\title{
ВОЗМОЖНОСТИ ПОЛУЧЕНИЯ МЕДИЦИНСКОЙ ПОМОЩИ СОТРУДНИКАМ МВД В РАМКАХ СУЩЕСТВУЮЩЕГО ЗАКОНОДАТЕЛЬСТВА РФ
}

Москаленко О.Л., Карпенко О.А., Филимонова Л.А., Згура Ю.А., Малышенко С.В., Яскевич Р.А.

В статье рассматриваются правовые аспекты получения медицинской помощи сотрудниками внутренних дел, показаны проблемы медиичинского обеспечения пациентов данной категории, как в медицинских организациях системы МВД, так и в сторонних медицинских учреждениях. Представлень возможности компромиссного подхода в обеспечении медицинской помощью сотрудников МВД на договорной основе между медицинскими организациями системы МВД и сторонними медицинскими организациями.

Ключевые слова: сотрудники органов внутренних дел; медицинская помощь; система обязательного медицинского страхования.

\section{HEPOSSIBILITY OF RECEIVING MEDICAL ASSISTANCE TO POLICE OFFICERS IN THE FRAMEWORK OF EXISTING LEGISLATION OF THE RUSSIA FEDERATION}

\author{
Moskalenko O.L., Karpenko O.A., Filimonova L.A., \\ Zgura Y.A., Malyshenko S.V., Yaskevich R.A.
}

The article deals with the legal aspects of obtaining medical care by employees of internal Affairs, shows the problems of medical care for patients in this category, both in medical organizations of the Ministry of internal Affairs, and in third-party medical institutions.

The possibilities of a compromise approach in providing medical care to the Ministry of internal Affairs on a contractual basis between medical orga- 
nizations of the Ministry of internal Affairs and third-party medical organizations are presented.

Keywords: employees of the internal Affairs bodies; medical care; the system of compulsory medical insurance.

Принципы работы ведомственной медицинской службы связаны с условиями профессиональной деятельности сотрудников органов внутренних дел, которая предполагает выполнение оперативных и боевых задач, включающих ненормированный рабочий день, применение огнестрельного оружия, работу в чрезвычайных ситуациях. Всё это сопровождается повышенной психологической и физической нагрузкой и нередко сопряжено с причинением вреда здоровью и риском для жизни. Основной задачей ведомственной медицины является проведение комплекса лечебно-профилактических мероприятий, позволяющих поддерживать высокий уровень здоровья и профпригодности у сотрудников органов внутренних дел и не допускать развития у данной категории каких- либо заболеваний и осложнений, способных привести к утрате трудоспособности и инвалидности [1].

Для того чтобы, рассмотреть вопрос возможности получения медицинской помощи сотрудникам МВД в рамках существующего правового поля, необходимо более детально изучить законодательную базу, регламентирующую предоставления медицинской помощи данной категории лиц. В соответствии с ч. 1 ст. 41 Конституции РФ каждый имеет право на охрану здоровья и медицинскую помощь. Медицинская помощь в государственных и муниципальных учреждениях здравоохранения оказывается гражданам бесплатно за счет средств соответствующего бюджета, страховых взносов, других поступлений [1].

Данный вопрос наиболее остро стоит при медицинском обеспечении сотрудников специализированной и высокотехнологичной медицинской помощью, которая нередко отсутствует в штате медицинских организаций системы МВД России; а также при медицинском обеспечении сотрудников в городах и иных населенных пунктах, удаленных от областных и краевых центров РФ, где расположены амбулаторно-поликлинические учреждения системы МВД России [2].

Организационно-штатная структура МСЧ и недостаточная лечебно-диагностической база не позволяют на уровне МСЧ проводить в полном объеме диагностику и лечение травм, психических расстройств и расстройств поведения. В связи с этим МСЧ выступает как посредник на этапе направ- 
ления сотрудников в специализированные лечебные учреждения. Потому одним из приоритетных направлений совершенствования ведомственного здравоохранения в современных условиях является формирование оптимальной организационной системы наблюдения и реабилитации сотрудников внутренних дел, участников боевых действий. [5]

При отсутствии по месту службы, месту жительства или иному месту нахождения сотрудника медицинских организаций федерального органа исполнительной власти отделений, соответствующего профиля, специалистов либо специального медицинского оборудования сотрудник имеет право на получение медицинской помощи в медицинских организациях государственной системы здравоохранения и муниципальной системы здравоохранения в порядке, установленном Правительством Российской Федерации. Расходы, связанные с оказанием медицинской помощи сотруднику, возмещаются медицинским организациям государственной системы здравоохранения и муниципальной системы здравоохранения в порядке, установленном Правительством Российской Федерации, за счет бюджетных ассигнований федерального бюджета, предусмотренных на эти цели федеральному органу исполнительной власти в сфере внутренних дел [4].

\section{Заключение}

Законодательством РФ предусмотрено следующее: сотрудник органов внутренних дел имеет право на бесплатное получение медицинской помощи в ведомственном медицинском учреждении, государственном или муниципальном лечебном учреждении или платное получение медицинской помощи. Оказание медицинской помощи сотрудникам МВД в медицинских организациях РФ осуществляется на основании договора «О возмещении затрат, связанных с оказанием медицинской помощи военнослужащим», заключенного между МВД и медицинской организацией []. Одним из приоритетных направлений совершенствования ведомственного здравоохранения является формирование оптимальной организационной системы для оказания всех видов медицинской помощи, включая профилактические и реабилитационные мероприятия.

\section{Список литературы}

1. Комплексные исследования по разработке системы охраны здоровья военнослужащих в условиях реформирования Вооруженных Сил Российской Федерации: материалы к отчету по теме КНИР / ВМА им. С.М. Кирова; рук. Тегза В.Ю.; исполн. Ивченко Е.В. СПб., 2007. 140 с. 
2. Миклошевич К.С. Медицинское обеспечение сотрудников органов внутренних дел // Вестник Восточно-Сибирского института МВД России. 2015. № 4. С. 75.

3. Постановление Правительства Российской Федерации от 30.12.2011г. № 1232 «О порядке оказания сотрудникам органов внутренних дел Российской Федерации, отдельным категориям граждан Российской Федерации, уволенных со службы в органах внутренних дел, и членам их семей медицинской помощи и их санаторно-курортного обеспечения».

4. Федеральный закон «О службе в органах внутренних дел Российской Федерации и внесении изменений в отдельные законодательные акты Российской Федерации» от 30 ноября 2012 г. N 342-Ф3 (с изм.) // Гарант эксперт: гарант-Максимум. Вся Россия / НПП «Гарант-сервис-университет». Версия от 01.03.2015.

5. Федеральный закон «О социальных гарантиях сотрудникам органов внутренних дел Российской Федерации и внесении изменений в отдельные законодательные акты Российской Федерации» от 19 июля 2011 г. N 247Ф3 (с изм.) // Гарант эксперт: гарант-Максимум. Вся Россия / НПП «Гарант-сервис-университет». Версия от 01.03.2015.

\section{References}

1. Kompleksnye issledovaniya po razrabotke sistemy ohrany zdorov'ya voennosluzhashchih v usloviyah reformirovaniya Vooruzhennyh Sil Rossijskoj Federacii: materialy k otchetu po teme KNIR [Comprehensive research on the development of a system of protecting the health of military personnel in the context of reforming the Armed Forces of the Russian Federation: materials on a report on the subject of the Scientific Research Policy]. BMA im. S.M. Kirova; ruk. Tegza V.YU.; ispoln. Ivchenko E.V. SPb., 2007. 140 s.

2. Mikloshevich K.S. Medicinskoe obespechenie sotrudnikov organov vnutrennih del [Medical support of internal affairs officers]. Vestnik Vostochno-Sibirskogo instituta MVD Rossii [Bulletin of the East Siberian Institute of the Ministry of Internal Affairs of Russia]. 2015. № 4. 75s.

3. Postanovlenie Pravitel’stva Rossijskoj Federacii ot 30.12.2011g. № 1232 «O poryadke okazaniya sotrudnikam organov vnutrennih del Rossijskoj Federacii, otdel'nym kategoriyam grazhdan Rossijskoj Federacii, uvolennyh so sluzhby v organah vnutrennih del, i chlenam ih semej medicinskoj pomoshchi i ih sanatorno-kurortnogo obespecheniya» [Resolution of the Government of the Russian Federation of December 30, 2011 No. 1232 "On the procedure for providing employees of the internal affairs bodies of the Russian Federation, certain categories of citizens of the Russian 
Federation who were dismissed from service in the internal affairs bodies, and their family members with medical assistance and sanatorium-and-spa services"].

4. Federal'nyj zakon «O sluzhbe v organah vnutrennih del Rossijskoj Federacii i vnesenii izmenenij v otdel'nye zakonodatel'nye akty Rossijskoj Federacii» ot 30 noyabrya 2012 g. N 342-FZ (s izm.) [The Federal Law "On service in the internal affairs bodies of the Russian Federation and Amendments to Certain Legislative Acts of the Russian Federation "dated November 30, 2012 N 342FZ (as amended)]. Garant ekspert: garant-Maksimum. Vsya Rossiya. NPP «Garant-servis-universitet». Versiya ot 01.03.2015.

5. Federal'nyj zakon «O social'nyh garantiyah sotrudnikam organov vnutrennih del Rossijskoj Federacii i vnesenii izmenenij v otdel'nye zakonodatel'nye akty Rossijskoj Federacii» ot 19 iyulya 2011 g. N 247-FZ (s izm.) [Federal Law “On Social Guarantees for Employees of the Internal Affairs Bodies of the Russian Federation and Amendments to Certain Legislative Acts of the Russian Federation" of July 19, 2011 N 247-FZ (as amended)]. Garant ekspert: garant-Maksimum. Vsya Rossiya. NPP «Garant-servis-universitet». Versiya ot 01.03.2015.

\section{ДАННЫЕ ОБ АВТОРАХ}

Филимонова Людмила Анатольевна, доцент кафедры пропедевтики внутренних болезней и терапии, кандидат медицинских наук, доцент ГБОУ ВПО «КрасГМУ им. проф. Ф.В. Войно-Ясенеикого» МЗ РФ ул. Партизана Железняка, 1а, г. Красноярск, 660022, Российская Федераиия selinala@mail.ru

Москаленко Ольга Леонидовна, старший научный сотрудник, кандидат биологических наук Федеральное государственное бюджетное научное учреждение «Научно-исследовательский институт медицинских проблем Севера» ул. Партизана Железняка, 32, г. Красноярск, 660022, Российская Федераиия gre-ll@mail.ru

Карпенко Ольга Анатольевна, заведующая приемным отделением Краевое государственное бюджетное учреждение здравоохранения Краевой Красноярский госпиталь для ветеранов войн ул. Вильского, 11, г. Красноярск, 660062, Российская Федераџия KOA.368@yandex.ru 
Малышенко Светлана Васильевна, заместитель начальника госпиталя по кадровым и правовым вопросам

Краевое государственное бюджетное учреждение здравоохранения Краевой Красноярский госпиталь для ветеранов войн ул. Вильского, 11, г. Красноярск, 660062, Российская Федерачия Svetianavm_06@mail.ru

Згура Юлия Александровна, доцент кафедры пропедевтики внутренних болезней и терапии, кандидат медицинских наук, доцент ГБОУ ВПО «КрасГМУ им. проф. Ф.В. Войно-Ясенецкого» МЗ РФ ул. Партизана Железняка, 1a, г. Красноярск, 660022, Российская Федераиия Yul::zg@yndex.ru

Яскевич Роман Анатольевич, доцент кафедры пропедевтики внутренних болезней и терапии, ведущий научный сотрудник, кандидат медицинских наук, доцент

ГБОУ ВПО «КрасГМУ им. проф. Ф.В. Войно-Ясенеикого» МЗ РФ; Федеральное государственное бюджетное научное учреждение «Научно-исследовательский институт медицинских проблем Севера» ул. Партизана Железняка, 1а, г. Красноярск, 660022, Российская Федерация; ул. Партизана Железняка, 32, г. Красноярск, 660022, Российская Федерация cardio@impn.ru

\section{DATA ABOUT THE AUTHORS}

Filimonova Lyudmila Anatolevna, associate professor at department of propedeutics of internal diseases and therapy, candidate of medical science, docent Krasnoyarsk State Medical University named after Professor V.F. Voino-Yasenetzkiy

1a, P. Zheleznyaka St., Krasnoyarsk, 660022, Russian Federation selinala@mail.ru

Moskalenko Olga Leonidovna, Senior Researcher, Candidate of Biological Sciences

Federal State Budgetary Scientific Institution «Scientific Research Institute of medical problems of the North» 
3g, Partizan Zheleznyaka str., Krasnoyarsk, 660022, Russian Federation gre-ll@mail.ru

Karpenko Olga Anatolevna, head of the reception

Regional state budgetary institution of health care Department Krasnoyarsk regional hospital for war veterans

11, Vilskogo str., Krasnoyarsk, 660062, Russian Federation

KOA.368@yandex.ru

Zgura Yulia Alexandrovna, associate professor at department of propedeutics of internal diseases and therapy, candidate of medical science, docent. Krasnoyarsk State Medical University named after Professor V.F. Voino-Yasenetzkiy

1a, P. Zheleznyaka St., Krasnoyarsk, 660022, Russian Federation Yul:.zg@yndex.ru

Malyshenko Svetlana Vasilyevna, Deputy head of the hospital for personnel and legal issues

Regional state budgetary institution of health care Department Krasnoyarsk regional hospital for war veterans

11, Vilskogo str., Krasnoyarsk, 660062, Russian Federation

Svetianavm_06@mail.ru

Yaskevich Roman Anatolyevich, associate professor at department of propedeutics of internal diseases and therapy, leading researcher, candidate of medical science, docent

Krasnoyarsk State Medical University named after Professor V.F. Voino-Yasenetzkiy; Federal State Budgetary Scientific Institution «Scientific Research Institute of medical problems of the North» 1a, P. Zheleznyaka St., Krasnoyarsk, 660022, Russian Federation; 3g, Partizan Zheleznyaka str., Krasnoyarsk, 660022, Russian Federation cardio@impn.ru 